\title{
RENDAS RELACIONAIS COMO FONTE DE VANTAGEM COMPETITIVA: UM ESTUDO DE CASO EM UMA EMPRESA CALÇADISTA DO ESTADO DA PARAÍBA
}

\section{RELATIONAL RENTS AS A SOURCE OF COMPETITIVE ADVANTAGE: A CASE STUDY IN A FOOTWEAR INDUSTRY}

\author{
Cinthia de Azevêdo Faustino ${ }^{1}$; Cláudia Fabiana Gohr ${ }^{2}$ \\ Universidade Federal da Paraíba - UFPB - João Pessoa/PB - Brasil \\ cinthiafaustino@gmail.com \\ Universidade Federal da Paraíba - UFPB - João Pessoa/PB - Brasil \\ claudiagohr@ct.ufpb.br
}

\begin{abstract}
Resumo
A formação de alianças entre empresas tem se tornado cada vez mais uma prática adotada para o alcance de vantagem competitiva. Este artigo analisa de que forma os relacionamentos interorganizacionais influenciam no desenvolvimento de vantagens competitivas sob a ótica da Visão Relacional. A visão relacional indica que os relacionamentos interorganizacionais podem gerar rendas relacionais, que são lucros obtidos conjuntamente entre os parceiros de uma rede. Existem basicamente quatro fontes de rendas relacionais: investimentos em ativos específicos de relacionamento, rotinas de compartilhamento de conhecimentos, complementaridade de recursos e governança. A partir da caracterização do relacionamento e das fontes de rendas relacionais, um procedimento de análise foi criado e aplicado por meio de um estudo de caso em uma indústria calçadista do Estado da Paraíba, empresa que faz parte de um APL representativo economicamente. Uma das constatações é que as rotinas de compartilhamento de conhecimento acontecem efetivamente, gerando lucros acima do normal que não poderiam ser gerados individualmente. No entanto, o investimento em ativos específicos ainda é uma fonte de renda relacional pouco explorada pela empresa.
\end{abstract}

Palavras-chave: vantagem competitiva; relacionamentos interorganizacionais; visão relacional; rendas relacionais.

\section{Introdução}

O ambiente concorrencial no qual as empresas estão inseridas atualmente exige que elas desenvolvam diferentes formas de se manterem competitivas. A Estratégia Empresarial surge como uma área do conhecimento que pode contribuir na investigação dos fatores que tornam uma empresa mais competitiva, com desempenho superior às demais.

No modelo clássico da Administração Estratégica, a estratégia se apresenta como uma escolha de combinações entre produtos e mercados (VASCONCELOS; CYRINO, 2000). Nessa 
perspectiva, os trabalhos de Michael Porter trazem contribuições significativas, com uma análise individual de como as empresas devem se posicionar no mercado e se proteger dos seus concorrentes. No entanto, outras pesquisas têm dado maior enfoque ao ambiente interno das organizações, ainda em uma análise individual, mas voltada à procura de fatores que podem explicar as diferenças de desempenho entre as empresas (GAGNON, 1999; WILK; FENSTERSEIFER, 2003; BARNEY; HESTERLY, 2007).

Dessa forma, Barney e Hesterly (2007) defendem que o gerenciamento estratégico passa pela combinação dessas duas fases: a análise externa, na qual as empresas identificam suas oportunidades e ameaças, e a análise interna, na qual identificam suas forças e fraquezas organizacionais. Na análise interna, a Visão Baseada em Recursos (VBR) surge como uma teoria capaz de descrever a forma como os recursos internos das empresas podem ser fonte de vantagem competitiva (WERNERFELT, 1984; BARNEY, 1991; PETERAF, 1993).

No entanto, Lavie (2006) afirma que a VBR considera as empresas como entidades individuais. Com o surgimento de novos formatos empresariais, como os arranjos produtivos, as empresas passaram a formar alianças que permitem o compartilhamento de recursos entre os parceiros. A VBR não conseguiu reconhecer essa característica em sua abordagem, o que possibilitou sua extensão para um estudo mais abrangente, que vai além da análise individual, considerando os relacionamentos interorganizacionais. Duas teorias comportam essa análise de recursos compartilhados, a Visão Baseada em Recursos Estendida (VBRE), proposta por Lavie (2006), e a Visão Relacional (VR), proposta por Dyer e Singh (1998).

Em especial, a visão relacional tem sido bastante empregada para analisar os relacionamentos interorganizacionais como fonte de vantagem competitiva. Pode-se citar como exemplo o trabalho desenvolvido por Viana, Barros Neto e Añez (2014) que investigaram a contribuição dos relacionamentos em uma cadeia de suprimentos para a obtenção de vantagem competitiva por empresas da indústria de calçados por meio da Visão Relacional. Outros trabalhos recentes também têm enfatizado a importância de uma análise relacional em empresas que atuam em diferentes arranjos interorganizacionais como fonte de vantagem competitiva, conforme pode ser observado na pesquisa de Gretzinger e Royer (2014) e Fawcett et al. (2015).

Neste contexto, este artigo pretende analisar de que forma os relacionamentos interorganizacionais influenciam no desenvolvimento de vantagens competitivas sob a ótica da Visão Relacional. A pesquisa será desenvolvida em uma indústria do setor calçadista do Estado da Paraíba por meio de um estudo de caso. Para o alcance do objetivo pretende-se: caracterizar o relacionamento da empresa investigada com as demais empresas e instituições com as quais interage; identificar as fontes de rendas relacionais, de acordo com a literatura consultada; e verificar como essas rendas podem influenciar na vantagem competitiva da empresa investigada. 
O estudo contribui para a literatura a medida que aborda uma temática recente, que necessita de revisões teóricas e aplicações práticas para torná-la mais consolidada (LEWIS et. al, 2010). Assim, a contribuição está na expansão do foco da empresa individual para redes interorganizacionais, com uma análise da interação de recursos através das fronteiras organizacionais (BARALDI; GRESSETVOLD; HARRISON, 2012).

$\mathrm{O}$ artigo está estruturado como segue. Na próxima seção são abordados os principais conceitos das teorias citadas anteriormente, especialmente a VBR e a VR. Em seguida, os procedimentos metodológicos são descritos, com a apresentação da empresa investigada e os instrumentos de coleta de dados utilizados. Na sequência, os resultados da pesquisa empírica são relatados e discutidos à luz da revisão bibliográfica. Por fim, as considerações finais, limitações e recomendações para futuras pesquisas são apontadas.

\section{Visão baseada em recursos (VBR)}

Ao longo dos anos, a abordagem dominante da organização industrial foi a visão voltada para o mercado, na qual as condições ambientais eram vistas como as principais responsáveis pelo aumento do desempenho (VASCONCELOS; CYRINO, 2000; BARNEY, 1991). Nessa perspectiva, as operações se ajustavam para seguir as regras ditadas pela concorrência (GAGNON, 1999). Com o aumento da competitividade entre as empresas, percebeu-se que olhar apenas para essas regras e para as necessidades dos clientes não era mais suficiente (DREJER, 2004). Assim, novas teorias surgiram a fim de identificar os motivos pelos quais as empresas se diferenciam no mercado competitivo, entre elas a Visão Baseada em Recursos.

De acordo com Barney (1991), a VBR considera os atributos idiossincráticos como influenciadores da vantagem competitiva. Assim, nessa abordagem, a fonte de vantagem competitiva duradoura advém dos recursos e das capacidades organizacionais, não da posição da empresa no mercado (RUMELT; SCHENDEL; TEECE, 1991). Gagnon (1999) defende ainda que, concentrando-se no desenvolvimento, proteção e alavancagem de recursos para obter vantagem em relação aos concorrentes, as empresas podem até mesmo alterar as regras do mercado.

Para Barney e Hesterly (2007), os recursos são ativos controlados pela empresa, sejam eles tangíveis ou intangíveis, que podem ser utilizados para criar e implementar suas estratégias. Para os autores, os recursos internos podem ser classificados como: recursos financeiros - dinheiro de empreendedores, acionistas, credores e bancos; recursos físicos - planta e equipamentos, localização geográfica, acesso à matéria-prima; recursos humanos - treinamento, experiência, julgamento, inteligência, relacionamentos, visão individual dos colaboradores; recursos organizacionais - estrutura de reporte da empresa, sistemas formais e informais de planejamento, 
controle e coordenação, cultura, reputação, relações informais dentro da empresa e entre a empresa e aqueles em seu ambiente.

Barney (1991) afirma que a VBR parte de duas considerações primordiais: os recursos são heterogêneos (ou seja, se diferenciam de empresa para empresa) e imóveis (não são facilmente transferíveis). A partir dessas considerações, Barney e Hesterly (2007) desenvolveram um modelo denominado VRIO (valor, raridade, inimitabilidade e organização), que explica como um recurso pode ser uma potencial fonte de vantagem competitiva sustentável. Assim, de acordo com os autores:

- Valor - um recurso é valioso se ele permite que a empresa explore uma oportunidade externa ou neutralize uma ameaça externa. Para isso, pode-se examinar o impacto de seu uso nas receitas e nos custos;

- Raridade - um recurso é raro quando não é controlado por inúmeros concorrentes;

- Inimitabilidade - um recurso é difícil de imitar quando as empresas concorrentes que não o possuem enfrentam desvantagem de custo para obtê-lo ou desenvolvê-lo. O custo da imitação advém de condições históricas únicas, ambiguidade causal, complexidade social e desenvolvimento de patentes;

- Organização - é preciso verificar se a empresa está organizada para explorar ao máximo o potencial dos seus recursos.

Assim, de acordo com o exposto pelo modelo VRIO, verifica-se que nem todos os recursos são estrategicamente importantes. Em sua pesquisa, Lin e Wu (2014) demonstraram que os recursos VRIO podem melhorar o desempenho da empresa e a influência dos recursos não-VRIO é insignificante. Outros autores afirmam ainda que, se vistos de forma isolada, recursos e capacidades são improdutivos (PERTUSA-ORTEGA; MOLINA-AZORÍN; CLAVER-CORTÉS, 2010). Dessa forma, a interação entre os recursos é que os tornam capazes de gerar vantagem competitiva, contribuindo para o desempenho superior das empresas em relação aos seus concorrentes.

Nota-se que, segundo a VBR, a vantagem competitiva advém de recursos que estão dentro dos limites da empresa, o que lhe confere propriedade e controle desses recursos, deixando uma lacuna sobre a questão da vantagem competitiva em ambientes de rede (LAVIE, 2006). As empresas estão sempre interligadas com outras empresas, o que favorece a interação de recursos externos que expande e complementa a base de recursos que, por sua vez, criam valor (BARALDI; GRESSETVOLD; HARRISON, 2012). Tomando como base esse aspecto, a próxima seção discute a visão relacional.

\section{Visão relacional (VR)}


A unidade de análise comumente citada na literatura sobre vantagens competitivas tem sido as empresas individuais, no entanto, recentemente a atenção tem sido voltada para empresas pertencentes a alianças, como cadeias de suprimentos e clusters, por exemplo (DYER; SINGH, 1998; WILK; FENSTERSEIFER, 2003). As alianças permitem o desenvolvimento de mecanismos de colaboração entre os parceiros e as empresas têm percebido cada vez mais os benefícios dessas associações, observando oportunidades que possibilitam responder mais rapidamente às demandas do mercado (CAO; ZHANG, 2011). Para Rungtusanatham et al. (2003), é preciso compreender a criticidade do desenvolvimento dessas ligações para desfrutar dos seus benefícios.

Nesta perspectiva de interligação entre as empresas, percebe-se que a VBR tradicional não reconheceu que, ao compartilharem recursos, as empresas podem obter os benefícios associados a eles (DYER; SINGH, 1998; LAVIE, 2006). Em sua teoria, denominada Visão Baseada em Recursos Estendida, Lavie (2006) aponta que a condição de imobilidade defendida pela VBR é enfraquecida à medida que as alianças permitem a transferência dos benefícios associados aos recursos dos parceiros.

A literatura aponta que os benefícios das alianças entre as empresas afetam o seu desempenho interno e o dos seus parceiros. Em sua pesquisa, Rungtusanatham et al. (2003) apontam que as ligações em uma cadeia de suprimentos podem ter um efeito direto ou indireto sobre o desempenho operacional. Wu et al. (2010) afirmam que os recursos compartilhados levam a diferenças de desempenho de empresas pertencentes a um cluster. Cao e Zhang (2011) defendem que a vantagem colaborativa gerada entre as empresas de uma cadeia aumenta o desempenho financeiro de cada parceiro. Dessa forma, verifica-se que o desempenho das empresas pode ser afetado pelos recursos transferidos entre os parceiros da aliança (LAVIE, 2006).

Para Dyer e Singh (1998), recursos interorganizacionais são denominados de recursos complementares, definidos como aqueles que, coletivamente, geram maiores lucros do que a soma dos recursos individuais dos parceiros de uma aliança. Uma categorização de recursos interorganizacionais é apresentada por Wilk (2006), no contexto de clusters. Os tipos de recursos identificados pelo autor são: recursos sistêmicos - aqueles que não pertencem às empresas individuais, que não há rivalidade em seu uso e podem ser compartilhados por todos da rede; recursos de acesso restrito - aqueles que não pertencem às empresas individuais, mas podem ser acessados de maneira privilegiada por apenas um grupo distinto de empresas.

Assim, além da análise do ponto de vista de recursos e capacidades individuais, é preciso levar em consideração os recursos compartilhados em conjunto pelas empresas (WILK; FENSTERSEIFER, 2003). Baraldi, Gressetvold e Harrison (2012), por exemplo, analisam a interação dos recursos que extrapolam os limites da empresa através das fronteiras organizacionais. Já Choi (2014) verificou em sua pesquisa se os recursos físicos e humanos implantados em relações 
interorganizacionais influenciam no desenvolvimento das capacidades das empresas, investigando se essas capacidades aumentam o desempenho das mesmas.

Nessa perspectiva, a Visão Relacional proposta por Dyer e Singh (1998) apresenta os relacionamentos interorganizacionais como geradores de vantagem competitiva, proporcionando a formação de rendas relacionais, que são lucros formados pelas relações de troca e que não poderiam ser geradas pelas empresas isoladamente.

Dyer e Singh (1998) apresentam quatro características que devem existir nos relacionamentos para a geração de rendas relacionais que proporcionem vantagem:

- Investimento em ativos específicos à relação;

- Troca de conhecimento que resulte em aprendizagem conjunta;

- Dotações complementares de recursos que resulte na criação conjunta de produtos, serviços e tecnologias;

- Mecanismos de governança eficazes que diminuam os custos de transação.

Gretzinger e Royer (2014), por meio de um estudo de caso com empresas da área de mecatrônica, energia limpa e refrigeração, que atuam em um cluster do Sul da Dinamarca, investigaram como a criação de valor em nível relacional pode ser sistematizada por meio de recursos compartilhados entre as empresas do cluster. Para tanto consideraram os mecanismos de rendas relacionais apresentados por Dyer e Singh (1998).

Um importante fator citado na literatura para a geração de benefícios a partir dos relacionamentos é a capacidade de absorção, que diz respeito à capacidade de assimilar conhecimentos dos parceiros a fim de melhorar seu desempenho (DYER; SINGH, 1998; CAO; ZHANG, 2011). Assim, os recursos existentes fora dos limites da empresa são tão importantes que podem até mesmo preceder a vantagem gerada pelos recursos internos (LEWIS et al, 2010).

Enfim, a Visão Baseada em Recursos se apoia nos recursos alojados dentro da empresa como fonte de geração de retornos; a Visão Relacional, em contrapartida, considera as rendas relacionais geradas conjuntamente e detidas por empresas parceiras como a principal fonte de vantagem competitiva (DYER; SINGH, 1998). Na sequência é apresentada uma breve caracterização dos relacionamentos interorganizacionais.

\section{Caracterização dos relacionamentos interorganizacionais}

Visto que a formação de alianças entre empresas é uma tendência cada vez mais forte do ambiente mercadológico, é preciso enxergar o desenvolvimento de arranjos empresariais como uma forma de criar e consolidar vantagens competitivas (BRITO; LEITE, 2008). Para Pigatto e Alcantara (2007), a tecnologia e o aumento da concorrência são fatores que têm alterado as formas 
de atuação das empresas, apontando para a necessidade de um maior entrosamento. Assim, os relacionamentos interorganizacionais oferecem maior legitimidade e visibilidade às empresas em relação aos seus stakeholders (HOCAYEN-DA-SILVA; TEIXEIRA, 2009).

Pigatto e Alcantara (2007) sintetizam algumas variáveis que caracterizam os relacionamentos entre empresas, que são: adaptação, confiança, comunicação, comprometimento, conflito, cooperação, cultura organizacional, dependência, investimento específico, poder e satisfação. A confiança também é citada por Sahay (2003), Cunha e Melo (2006) e Fawcett, Jones e Fawcett (2012), quando indicam que a medida que o relacionamento se desenvolve, o nível de confiança aumenta e torna-se mais fácil lidar com as incertezas. Assim, o tempo é considerado uma variável importante no contexto das interligações entre as empresas, pois a ele vinculam-se características como confiança e conhecimento acumulado (CASTRO; BULGACOV; HOFFMANN, 2011).

Cunha e Melo (2006) apontam a colaboração como uma característica marcante nos relacionamentos, defendendo que ela acontece quando há confiança, favorecendo o desenvolvimento de um ciclo de aprendizagem. Dessa forma, as empresas colaboram para compartilhar tanto dados e informações, quanto benefícios e riscos (PARUNG; BITITCI, 2006). É importante considerar a necessidade de relacionar a individualidade das empresas, que se mantém mesmo quando estão inseridas em alianças, e a coletividades dos relacionamentos (CASTRO; BULGACOV; HOFFMANN, 2011).

$\mathrm{Na}$ literatura há diversas classificações de relacionamentos interorganizacionais. Brito e Leite (2008) apresentam esses relacionamentos como arranjos empresariais, categorizados nos seguintes tipos: filière, cadeia de suprimentos, cooperativa, redes, condomínio industrial, consórcio modular, cluster e APL (arranjo produtivo local). Parung e Bititci (2006) caracterizam quatro tipos de redes colaborativas: cadeias de suprimentos, empresas estendidas, empresas virtuais e clusters. Como a unidade de análise desta pesquisa é classificada como integrante de um APL, no Quadro 1 são apresentadas duas definições desse tipo de relacionamento interorganizacional.

Quadro 1 - Definições de Arranjo Produtivo Local

\begin{tabular}{|c|l|}
\hline Autor/Órgão (ano) & \multicolumn{1}{c|}{ Definição } \\
\hline Sebrae (2009) & $\begin{array}{l}\text { Aglomeração de empresas, localizada em um mesmo território, que apresenta } \\
\text { especialização produtiva e mantém algum vínculo de articulação, interação, cooperação e } \\
\text { aprendizagem entre si e com outros atores locais, tais como: governo, associações } \\
\text { empresariais, instituições de crédito, ensino e pesquisa. }\end{array}$ \\
\hline \multirow{3}{\text{Gonçalves,LeiteeSilva}}{$\begin{array}{l}\text { Aglomerações ou concentrações territoriais e setoriais de agentes econômicos, políticos e } \\
\text { sociais em torno de uma atividade econômica específica, nas quais se estruturam } \\
\text { (2012) }\end{array}$} & $\begin{array}{l}\text { parnculos e relações de interação, interdependência, cooperação e aprendizagem, voltadas } \\
\text { competitividade e sustentabilidade dos seus membros, como também para a promoção do } \\
\text { dinamismo econômico local da região em que o APL está inserido, diminuindo as } \\
\text { disparidades intra e inter-regionais. }\end{array}$ \\
\hline
\end{tabular}

Fonte: Autoria própria (2015) a partir dos autores citados 
$\mathrm{Na}$ próxima seção são apresentados os procedimentos metodológicos que permitiram a realização do estudo empírico.

\section{Procedimentos metodológicos}

Para o alcance do objetivo, a investigação apresentada neste artigo foi baseada em um estudo de caso, procedimento que permite uma apreciação mais aprofundada e o conhecimento detalhado da unidade de análise estudada (YIN, 2005). O trabalho é desenvolvido a partir da análise de uma empresa no contexto dos seus relacionamentos interorganizacionais.

A empresa objeto de investigação faz parte de uma organização de capital aberto que atua no segmento de calçados, vestuários e acessórios das marcas Havaianas, Dupé, Topper, Rainha, Mizuno, Timberland, Sete Léguas e Osklen. No Brasil, a empresa está sediada no Estado de São Paulo e possui 13 unidades de produção; há ainda fábricas instaladas na Argentina e 7 escritórios espalhados pelo mundo (na Espanha, Itália, Inglaterra, França, Portugal Alemanha e Estados Unidos). A unidade de análise da presente pesquisa é uma das fábricas do grupo, localizada em um município do Estado da Paraíba. A seleção da empresa se deu por ela pertencer a um APL representativo para o estado da Paraíba e também pelo critério de acessibilidade.

As etapas de execução do trabalho estão apresentadas no Quadro 2, juntamente com as atividades realizadas e os instrumentos de coleta de dados utilizados em cada etapa.

Quadro 2 - Etapas da pesquisa

\begin{tabular}{|l|l|l|}
\hline \multicolumn{1}{|c|}{ Etapas } & \multicolumn{1}{|c|}{ Atividades } & \multicolumn{1}{c|}{$\begin{array}{c}\text { Instrumento de Coleta de Dados / } \\
\text { Análise de dados }\end{array}$} \\
\hline Revisão da literatura & $\begin{array}{l}\text { Busca por artigos científicos sobre a temática } \\
\text { em estudo. }\end{array}$ & - Pesquisa bibliográfica. \\
\hline $\begin{array}{l}\text { Desenvolvimento do } \\
\text { procedimento de análise }\end{array}$ & $\begin{array}{l}\text { Elaboração do procedimento de análise para a } \\
\text { construção dos instrumentos de coleta de dados } \\
\text { e para auxiliar na análise da pesquisa de campo. }\end{array}$ & - Pesquisa bibliográfica. \\
\hline Pesquisa de campo & $\begin{array}{l}\text { Identificação das fontes de rendas relacionais na } \\
\text { empresa objeto de investigação. }\end{array}$ & $\begin{array}{l}\text { - Entrevista semiestruturada; } \\
\text { - Observação participante. }\end{array}$ \\
\hline Análise dos resultados & $\begin{array}{l}\text { Análise das informações coletadas na pesquisa } \\
\text { de campo. }\end{array}$ & $\begin{array}{l}\text { - Análise do conteúdo das } \\
\text { informações. }\end{array}$ \\
\hline
\end{tabular}

Fonte: Autoria própria (2015)

A principal fonte bibliográfica para a construção da revisão da literatura foram artigos publicados em periódicos internacionais, mas também foram consultados artigos nacionais, teses e dissertações relacionadas à temática em estudo. As categorias de análise foram construídas com base nas características dos relacionamentos interorganizacionais levantadas na revisão teórica e nas quatro características apresentadas por Dyer e Singh (1998) como determinantes de rendas relacionais, também apontadas na revisão, conforme pode ser visualizado nos Quadros 3 e 4, juntamente com as questões da entrevista semiestruturada. O Quadro 3 contém as categorias 
relacionadas à caracterização do relacionamento, enquanto o Quadro 4 contém as características que determinam a geração de rendas relacionais.

Para a pesquisa de campo buscou-se mais de uma fonte de coleta de dados que, segundo Yin (2001), possibilita que se obtenha convergência de informações de diferentes origens, aumentando a confiabilidade do estudo de caso. As entrevistas semiestruturadas foram realizadas nos meses de agosto e setembro de 2015. Além da entrevista semiestruturada, também utilizou-se a observação participante para auxiliar na constatação da veracidade de parte das informaçõs obtidas, pois uma das autoras desta pesquisa desenvolveu atividade de estágio na empresa investigada. Por meio da observação foi possível verificar no cotidiano da empresa algumas características de relacionamento dela com outras empresas e entidades, assim como aspectos relacionados às rendas relacionais. Em seguida os resultados são descritos e analisados.

A pesquisa de campo foi realizada no mês de setembro de 2015. A entrevista semiestruturada foi aplicada de forma presencial com gravação e duração de 50 minutos. O entrevistado foi um analista do setor de qualidade que trabalha na empresa há 8 anos, atuando nos processos de verificação da qualidade das matérias-primas que chegam à fábrica. A análise dos resultados foi feita a partir dos dados obtidos na pesquisa de campo, por meio da observação participante e entrevista, sob a ótica da teoria apresentada na revisão teórica, especificamente a Visão Relacional.

Nesse contexto, foram analisados os conteúdos das informações e, em seguida, as informações foram categorizadas, segundo as categorias de pesquisa definidas na pesquisa (Quadros 3 e 4).

\begin{tabular}{|c|c|c|}
\hline $\begin{array}{c}\text { Característica do } \\
\text { relacionamento }\end{array}$ & Descrição & Questão \\
\hline \multirow{4}{*}{$\begin{array}{l}\text { Vínculo com atores } \\
\text { locais }\end{array}$} & \multirow{4}{*}{$\begin{array}{l}\text { Relacionamento } \\
\text { que a empresa } \\
\text { estabelece com } \\
\text { outras empresas ou } \\
\text { órgãos de apoio. }\end{array}$} & $\begin{array}{l}\text { 1. A empresa se relaciona com outras empresas do arranjo } \\
\text { (fornecedores, concorrentes, distribuidores)? }\end{array}$ \\
\hline & & 2. A empresa se relaciona com instituições de pesquisa? Quais? \\
\hline & & 3. A empresa se relaciona com órgãos como o Senai e o Sebrae? \\
\hline & & 4. Como se dá o relacionamento da empresa com o sindicato? \\
\hline \multirow[b]{2}{*}{$\begin{array}{l}\text { Confiança/ } \\
\text { Colaboração }\end{array}$} & \multirow{2}{*}{$\begin{array}{l}\text { Características que } \\
\text { elevam a } \\
\text { competitividade do } \\
\text { arranjo como um } \\
\text { todo. }\end{array}$} & $\begin{array}{l}\text { 5. Você acredita que há confiança nos relacionamentos que a } \\
\text { empresa desenvolve com as demais empresas do arranjo } \\
\text { (fornecedores, concorrentes, distribuidores)? }\end{array}$ \\
\hline & & $\begin{array}{l}\text { 6. Você acredita que há colaboração nos relacionamentos que a } \\
\text { empresa desenvolve com as demais empresas do arranjo } \\
\text { (fornecedores, concorrentes, distribuidores), a fim de contribuir } \\
\text { para o desenvolvimento regional? }\end{array}$ \\
\hline
\end{tabular}

Fonte: Autoria própria (2015) 
Quadro 4 - Categorias de análise para fontes de rendas relacionais

\begin{tabular}{|c|c|c|}
\hline $\begin{array}{l}\text { Determinantes de } \\
\text { rendas relacionais }\end{array}$ & Descrição & Questão \\
\hline \multirow{3}{*}{$\begin{array}{l}\text { Ativos específicos de } \\
\text { relacionamento }\end{array}$} & \multirow{3}{*}{$\begin{array}{l}\text { Algo especializado em } \\
\text { um relacionamento que } \\
\text { as empresas fazem para } \\
\text { desenvolver uma } \\
\text { vantagem competitiva. } \\
\text { Os ativos podem ser } \\
\text { físicos, humanos ou } \\
\text { locacionais. }\end{array}$} & $\begin{array}{l}\text { 1. A empresa realiza investimentos em conjunto com outras } \\
\text { empresas em ativos específicos de relacionamento (físicos, } \\
\text { humanos, locacionais)? Se sim, de que forma? }\end{array}$ \\
\hline & & $\begin{array}{l}\text { 2. Os investimentos em ativos específicos geram garantias } \\
\text { para as empresas que participaram do investimento? Como? }\end{array}$ \\
\hline & & $\begin{array}{l}\text { 3. O relacionamento mais estreito com determinadas empresas } \\
\text { facilita o maior investimento em ativos específicos? Por } \\
\text { quê? }\end{array}$ \\
\hline \multirow{5}{*}{$\begin{array}{l}\text { Rotinas de } \\
\text { compartilhamento de } \\
\text { conhecimento }\end{array}$} & \multirow{5}{*}{$\begin{array}{l}\text { Interações entre as } \\
\text { empresas que permitem a } \\
\text { transferência e a criação } \\
\text { de conhecimento, } \\
\text { levando à aprendizagem } \\
\text { conjunta. }\end{array}$} & $\begin{array}{l}\text { 4. A empresa considera as demais empresas do arranjo como } \\
\text { fontes de ideias e informações que resultam em inovação? }\end{array}$ \\
\hline & & 5. Que tipos de informações são trocadas entre as empresas? \\
\hline & & $\begin{array}{l}\text { 6. Há interações frequentes entre as empresas para a } \\
\text { transferência de conhecimento? De que forma isso } \\
\text { acontece? }\end{array}$ \\
\hline & & $\begin{array}{l}\text { 7. A empresa passou a adotar algum método aprendido de } \\
\text { outra empresa? }\end{array}$ \\
\hline & & $\begin{array}{l}\text { 8. Há interações informais entre colaboradores da empresa e } \\
\text { colaboradores de outras empresas? }\end{array}$ \\
\hline \multirow{3}{*}{$\begin{array}{l}\text { Complementaridade } \\
\text { de recursos e } \\
\text { capacidades }\end{array}$} & \multirow{3}{*}{$\begin{array}{l}\text { Recursos distintos dos } \\
\text { parceiros que não } \\
\text { poderiam ser adquiridos } \\
\text { em um mercado } \\
\text { secundário. }\end{array}$} & $\begin{array}{l}\text { 9. A empresa compartilha recursos com outras empresas? Que } \\
\text { tipos de recursos? }\end{array}$ \\
\hline & & $\begin{array}{l}\text { 10. A empresa realiza projetos em conjunto com outras } \\
\text { empresas? Há situações em que outras empresas participam } \\
\text { do desenvolvimento de novos produtos da empresa? }\end{array}$ \\
\hline & & $\begin{array}{l}\text { 11. A empresa considera a reputação de outras empresas para } \\
\text { desenvolver relacionamentos? }\end{array}$ \\
\hline \multirow{5}{*}{ Governança efetiva } & \multirow{5}{*}{$\begin{array}{l}\text { Mecanismo de proteção } \\
\text { contra o oportunismo. } \\
\text { Pode ser autoaplicada ou } \\
\text { dependente de uma } \\
\text { terceira parte. }\end{array}$} & 12. Existe algum órgão regulador para a indústria calçadista? \\
\hline & & $\begin{array}{l}\text { 13. A empresa possui algum tipo de contrato formal com outras } \\
\text { empresas do arranjo? }\end{array}$ \\
\hline & & 14. Há casos nos quais a confiança rege o relacionamento? \\
\hline & & $\begin{array}{l}\text { 15. De que forma a empresa se protege de comportamentos } \\
\text { oportunistas com as outras empresas do arranjo? }\end{array}$ \\
\hline & & 16. Caso haja comportamentos oportunistas, há punição? \\
\hline
\end{tabular}

Fonte: Autoria própria (2015) a partir de Dyer e Singh (1998)

\section{Descrição e discussão dos resultados}

De posse das informações coletadas na pesquisa de campo, nesta seção a empresa objeto de investigação será descrita e analisada sob a ótica da teoria que conduziu o estudo empírico, a Visão Relacional.

\subsection{Descrição dos relacionamentos interorganizacionais}

Conforme destacado anteriormente, a empresa investigada faz parte do APL de calçados do estado da Paraíba. Por ser uma organização de grande porte, ela torna-se influente na execução das atividades desse arranjo. Um fato que comprova essa constatação é que a empresa gera grande quantidade de empregos diretos, além de atrair outras empresas para o estado, como é o caso de fornecedores de matérias-primas como atacador, palmilha e espumas, que se instalaram no estado devido ao fornecimento à empresa analisada. Verifica-se, assim, que a empresa contribui para o desenvolvimento municipal e estadual à medida que favorece a geração de emprego e renda. No 
entanto, o entrevistado indicou que grande parte das matérias-primas que agregam valor aos produtos são oriundas das regiões Sul e Sudeste, indicando que a contribuição da empresa poderia ser ainda maior se comprasse de fornecedores mais próximos, até mesmo da região Nordeste.

A empresa mantém um relacionamento próximo com o SENAI (Serviço Nacional de Aprendizagem Industrial), órgão que colabora na execução de atividades como testes de laboratório e calibração de quipamentos, extremamente necessárias à manutenção dos padrões de qualidade dos materiais. Também há relacionamento com o IBTEC (Instituto Brasileiro de Tecnologia do Couro, Calçado e Artefatos), que realiza testes de calçados quando não há determinado maquinário na empresa para avaliar os parâmetros que as normas estabelecem. Há parcerias com universidades na contratação de estudantes para realizar atividades de estágio e de professores consultores na execução de projetos específicos, como é o caso do programa de ergonomia. A organização também se relaciona com empresas de consultoria que auxiliam na busca de soluções e na implementação de novas ferramentas.

Na pesquisa verificou-se que a empresa acredita que há um relacionamento de confiança e colaboração com as empresas com as quais a unidade de análise se relaciona, pois busca-se estabelecer relações estreitas e de apoio mútuo na resolução de problemas e na aprendizagem contínua. O tempo é uma variável que contribui na permanência dos relacionamentos, como é o caso de fornecedores que ao longo dos anos foram construindo confiança a partir da relação de parceria e do cumprimento das especificações requisitadas.

\subsection{Descrição das fontes de rendas relacionais}

Como apresentado na revisão teórica, a Visão Relacional de Dyer e Singh (1998) aponta quatro fatores que podem ser fontes de rendas relacionais: ativos específicos de relacionamentos, rotinas de compartilhamento de conhecimento, complementaridade de recursos e governança. Nesta subseção essas quatro características são descritas de acordo com as informações coletadas.

\subsubsection{Ativos específicos de relacionamento}

Os investimentos em ativos específicos não é comumente verificado na empresa, mas já houveram casos em que foi necessário algum tipo de investimento para garantir determinadas atividades. Um exemplo foi o financiamento que a organização realizou para que o proprietário de um curtume pudesse importar o couro e realizar o acabamento conforme a empresa necessitava. Houve outro caso em que a empresa investiu em um fornecedor de cabides, quando ele não possuia as características necessárias para ser homologado, assim a empresa resolver investir em ativos físicos que pudessem dar suporte à estruturação do seu negócio. 
Nos casos apresentados, nota-se que por a empresa possuir um porte bastante superior aos dos seus fornecedores, ela acaba investindo em ativos que possam alavancar a competitividade dos seus parceiros, o que também favorecerá a melhoria dos seus processos. Os trâmites legais são definidos nos contratos, de modo que o parceiro possa realizar o pagamento dos investimentos realizados. Os relacionamentos mais estreitos e que oferecem garantias de atendimento à qualidade e à demanda requeridas estão mais propícios à realização de investimentos em ativos específicos.

\subsubsection{Rotinas de compartilhamento de conhecimento}

O compartilhamento de conhecimento é uma característica mais forte da empresa. Ela considera que os seus fornecedores são grandes fontes de ideias e informações, pois são eles que possuem o know how dos seus processos. A fabricação de calçados é uma atividade que necessita de um grande número de matérias-primas e, por se tratar de um processo extremamente manufatureiro, ele está vulnerável a inúmeros problemas inerentes ao processo.

Dessa forma, quando a investigação interna de problemas elimina as variáveis de processo (por exemplo, máquinas ajustadas, tempos corretos e operadores experientes), recorre-se aos parceiros para que a análise seja realizada conjuntamente. No caso de matérias-primas defeituosas, o fornecedor é acionado para visitar a empresa e acompanhar o processo a fim de identificar as possíveis causas de problemas; neste caso, o fornecedor participa até mesmo de grupos de melhoria contínua. Há situações em que as empresas solicitam aos consultores ideias que possam contribuir na resolução de problemas. Neste caso, como os consultores acompanham projetos de diverentes sistemas produtivos, lidando com uma grande variedade de situações, a interação gera troca de conhecimento que, por sua vez, cria aprendizagem conjunta. Assim, acontecem trocas constantes a partir do surgimento de problemas de processo.

Outra forma de interação com os parceiros é no desenvolvimento de novos produtos. A empresa participa de feiras de calçados onde a troca de ideias e apresentação de inovações do setor favorecem o compartilhamento de conhecimento. $\mathrm{O}$ setor de desenvolvimento interage bastante com os parceiros na busca de novidades e soluções, especialmente por se tratarem de produtos relacionados à moda, que requerem inovação de materiais e cores, por exemplo. Percebe-se que a troca de conhecimentos na fase de desenvolvimento de novos produtos é de extrema importância, pois isso irá afetar as características dos produtos e processos e implicará no nível de aceitação do consumidor final. A aprendizagem vai acontecer a medida que a empresa desenvolve a sua capacidade de absorção de conhecimento.

Outro fator que auxilia nas rotinas de compartilhamento de conhecimento são as relações informais entre colaboradores de empresas parceiras. Verifica-se que no caso dos fornecedores, por exemplo, no primeiro momento as relações são mais formais a fim de apresentar os padrões que 
foram estabelecidos pelas empresas; no entanto, no decorrer do tempo os relacionamentos informais vão se intensificando e se tornando fator de geração de conhecimento. Como representantes das empresas, os colaboradores passam a ter papel fundamental na criação da aprendizagem a partir das interações informais.

\subsubsection{Complementaridade de recursos}

A característica de complementaridade de recursos está relacionada ao compartilhamento de conhecimentos apresentado anteriormente, pois está voltada para interações capazes de gerar lucros coletivos, e um dos recursos complementares mais facilmente identificado é o próprio conhecimento. Esse recurso se torna complementar a medida que uma empresa o possui, seja na forma de conhecimento tácito ou explícito, e o parceiro é capaz de assimilá-lo e utilizá-lo na resolução de problemas, na participação de projetos ou no desenvolvimento de novos produtos, como já foi descrito.

Um fator que contribui para a dotação de recursos complementares é a reputação das empresas parceiras. De acordo com Dyer e Singh (1998) é preciso que haja compatibilidade organizacional para que as empresas possam se beneficiar de recursos complementares; uma das características dessa compatibilidade é a cultura organizacional. Verificou-se que a empresa objeto de investigação busca compatibilidade com seus parceiros em relação à reputação, como por exemplo na seleção dos seus fornecedores, quando são avaliados critérios como a imagem da empresa no mercado e o seu compromisso com questões trabalhistas e ambientais. O rigor com a reputação, no caso analisado, se dá especialmente com os produtos de exportação que irão para mercados extremamente exigentes em relação à composição e fabricação de produtos.

O compartilhamento de recursos pode acontecer de maneira informal, como citado pelo entrevistado. Já houveram casos de outras empresas necessitarem de materiais ou máquinário e a empresa realizar um empréstimo, que se deu de forma amigável, não havendo necessidade de elaboração de contratos para isso.

\subsubsection{Governança}

A governança se relaciona com a complementaridade de recursos à medida que considera a reputação como um fator importante nos relacionamentos; esse fator foi abordado anteriormente. Não verificou-se a existência de relacionamentos com empresas parceiras unicamente por meio de confiança, o que Dyer e Singh (1998) chamaram de mecanismos de autoaplicação informais, mas sim a aplicação de mecanismos de autoaplicação formais, regidos por meio de contratos.

Em relação ao relacionamento com os fornecedores, o mecanismo de proteção contra comportamentos oportunistas é basicamente os contratos. No entanto, as relações informais já 
descritas favorecem a diminuição desse tipo de comportamento. Além disso, como a empresa investigada trata-se de uma organização de grande porte, os fornecedores buscam atender de forma satisfatória aos requisitos exigidos a fim de manter os contratos de fornecimento. Como os fornecedores são avaliados mensalmente por meio de indicadores, é possível avaliar o cumprimentos dos acordos estabelecidos. Se há problemas, a empresa busca verificar junto com o fornecedor as possíveis causas de seus problemas, para que se possa encontrar soluções conjuntamente. A governança autoaplicada deixa os relacionamentos mais estreitos, desde que os parceiros mantenham os compromissos assumidos. Como afirmou o entrevistado, não há condições de manter um fornecedor extremamente irregular.

\subsection{Discussão dos resultados}

De acordo com o que foi apresentado, pode-se analisar algumas questões acerca das fontes de vantagem competitiva oriundas dos relacionamentos interorganizacionais da empresa objeto de investigação. Verifica-se que o investimento em ativos específicos ainda é uma característica pouco explorada pela empresa. Há teorias que afirmam que o investimento nesses ativos deve ser evitado devido aos elevados custos que podem ser incorridos no processo; no entanto, a Visão Relacional sugere que os ativos específicos geram vantagem competitiva para as empresas que realizam o investimento. No caso analisado pode-se afirmar que a empresa não usufrui das rendas relacionais que poderiam ser geradas a partir dessa prática, o que aponta para uma oportunidade de investimentos futuros.

As rotinas de compartilhamento de conhecimento são uma fonte mais efetiva de vantagem competitiva verificada na prática, pois a empresa aposta na interação com os seus parceiros a fim de compartilhar e criar novos conhecimentos, prática que leva à aprendizagem conjunta. Esse é um fator positivo nas relações interorganizacionais que a empresa estabelece. Como afirma Cunha (2006), a medida que os parceiros utilizam oportunidade para se mostrarem confiáveis, ocorre o desenvolvimento de um ciclo de aprendizagem virtuoso, favorecendo a colaboração cada vez mais forte entre as empresas.

A complementaridade de recursos é uma característica que pode ser mais explorada, especialmente em relação ao efetivo compartilhamento de recursos físicos, por meio da avaliação do alinhamento entre as estratégias pretendidas. Como defendido por Lavie (2006), a propriedade dos recursos não é necessariamente uma condição para a vantagem competitiva, pois essa característica desconsidera a contribuição que os recursos da aliança podem oferecer. Investir em recursos complementares pode fortalecer os relacionamentos e gerar vantagem competitiva conjunta. É necessário analisar a interação dos recursos que extrapolam os limites da empresa através das fronteiras organizacionais (BARALDI; GRESSETVOLD; HARRISON, 2012). 
Em relação à governança efetiva, percebeu-se que os mecanismos de autoaplicação formais são bem explorados, o que gera rendas relacionais e, consequentemente, vantagem competitiva a partir dos relacionamentos. Para que essa vantagem seja ainda mais favorável, a empresa deve buscar desenvolver a autoaplicação de maneira cada vez mais informal, a fim de dificultar a imitação por parte dos concorrentes e obter os benefícios desse tipo de autoaplicação. Para isso, é necessário que os relacionamentos sejam mais baseados na confiança, a fim de que os benefícios comuns que não poderiam ser gerados individualmente se tornem perceptíveis (DYER; SINGH, 1998; CAO; ZANGH, 2011).

Como afirmado por Cao e Zhang (2011), a vantagem colaborativa é resultado da vantagem competitiva conjunta. Fortalecer as fontes de rendas relacionais poderá oferecer à empresa maior possibilidade de aumentar os seus lucros a partir dos relacionamentos interorganizacionais que estabelece e, consequentemente, fortalecer a vantagem do cluster do qual faz parte.

\section{Considerações finais}

$\mathrm{O}$ interesse em investigar a vantagem competitiva gerada dos relacionamentos interorganziacionais vêm crescendo devido à formação cada vez maior de alianças entre empresas. A partir da revisão teórica foi possível verificar que a Visão Relacional é uma das principais teorias que apontam a rede como unidade de análise fundamental. Partindo da caracterização dos relacionamentos interorganizacionais que a empresa objeto de investigação estabelece e da identificação das possíveis fontes de rendas relacionais, foi possível discutir sobre os benefícios que a empresa obtém a partir dos relacionamentos e as fontes que podem ser mais exploradas da relação para que a vantagem conjunta seja ainda mais efetiva.

Dessa forma, na prática, é importante que a empresa conheça as fontes de rendas relacionais e verifique se tem usufruído dos seus benefícios. No caso analisado, a fonte mais efetiva de renda relacional é a rotina de compartilhamento de conhecimento, que gera aprendizagem conjunta entre a empresa e os seus parceiros, especialmente seus fornecedores. O investimento em ativos específicos é uma atividade esporádica, pouco explorada pela empresa, indicando que ela deixa de obter os benefícios dessa fonte mas, ao mesmo tempo, torna-se uma oportunidade de geração de renda relacional. As dotações de recursos complementares e a governança são parcialmente executadas, o que também aponta para a possibilidade de empregar esforços que busquem desfrutar dessas fontes nos relacionamentos.

O trabalho também traz contribuições teóricas por investigar uma temática recente e crescente nas pesquisas acadêmicas, a análise dos relacionamentos como fonte de vantagem competitiva. Partindo das categorias de análise levantadas, outros trabalhos podem confrontar os resultados apresentados pela empresa focal com informações obtidas de seus parceiros, ampliando o 
foco de investigação. Pode-se, ainda, realizar um survey com todas as empresas do cluster de forma a ampliar o grau de generalização dos resultados. Outra oportunidade seria a investigação dos mecanismos de proteção das rendas relacionais no arrranjo investigado, ou ainda em outros setores e arranjos distintos. Trabalhos futuros também podem utilizar as categorias de análise levantadas para replicar a aplicação realizada nesta pesquisa em clusters de outros setores produtivos.

\begin{abstract}
The networks are an important strategy that has been used by the companies to achieve competitive advantage. Through the relational view, this article aims to analyze how inter-organizational network can influence in the competitive advantage. The relational view is a theory who indicates that inter-organizational network can generate relational rents, a supernormal profit jointly generated in an exchange relationship. There are basically four sources of relational rents from the relationship between organizations: investments in specific assets relationship, knowledge sharing routines, complementary resources and governance. From description of the relationship by the company studied and the sources of relational rents from the literature a framework was created and applied through a case study in a footwear industry of the state of Paraiba, a company that is part of an important cluster of the state. One of the findings is that knowledge sharing routines occurs in the company and this can generate supernormal profits that could not generated individually. However, the relation specific assets are a source of relational rent underexplored by the firm.
\end{abstract}

Key-words: competitive advantage; inter-organizational relationships; relational view; relational rents.

\title{
Referências
}

BARNEY, J. Firm resource and sustained competitive advantage. Journal of Management, v. 17, n. 1, p. 99-120, 1991. cross ref

BARNEY, J. B.; HERSTERLY, W. Administração estratégica e vantagem competitiva: casos brasileiros. São Paulo: Pearson Prentice Hall, 2007.

BARALDI, E.; GRESSETVOLD, E.; HARRISON, D. Resource interaction in inter-organizational networks: Foundations, comparison, and a research agenda. Journal of Business Research, v. 65, n. 2, p. 266-276, 2012. crossref

BRITO, A. M.; LEITE, M. S. A. Discussão sobre as características dos diferentes arranjos empresariais. In: XXVIII Encontro Nacional de Engenharia de Produção, Rio de Janeiro, RJ, Brasil, 13 a 16 de outubro de 2008. Disponível em: <http://www.abepro.org.br/biblioteca/enegep2008_TN_WIC_075_534_11343.pdf>. Acesso em: 08 set. 2015.

CAO, M., ZHANG, Q. Supply chain collaboration: impact on collaborative advantage and firm performance. Journal of Operations Management, v. 29, n. 3, p. 163-180, 2011. crossref

CASTRO, M.; BUGACOV, S.; HOFFMANN, V. E. Relacionamentos interorganizacionais e resultados: estudo em uma rede de cooperação horizontal da região central do Paraná. Revista de Administração Contemporânea, v. 15, n. 1, p. $25-46,2011$. cross ref

CHOI, S. Developing relationship-specific memory and absorptive capacity in interorganizational relationships. Inf . Technol. Management, v. 15, p. 23-238, 2014. crossref

CUNHA, C. R.; MELO, M. C. O. L. A confiança nos relacionamentos interorganizacionais: o campo da biotecnologia em análise. RAE-eletrônica, v. 5, n. 2, 2006. crossref 
DREJER, A. Back to basics and beyond Strategic management: an area where practice and theory are poorly related. Management Decision, v. 42, n. 3/4, p. 508-520, 2004. crossref

DYER, J. H.; SINGH, H. The relational view: cooperative strategy and sources of interorganizational competitive advantage. Academy of Management Review, v. 23, n. 4, p. 660-679, 1998.

FAWCETT, S. E.; JONES, S.L.; FAWCETT, A. M. Supply chain trust: the catalyst for collaborative innovation. Business Horizons, v. 55, n. 2, p. 163-178, 2012. crossref

FAWCETT, S. E. et al. Why supply chain collaboration fails: the socio-structural view of resistance to relational strategies. Supply Chain Management, v. 20, n. 6 p. 648 - 663, 2015. crossref

GAGNON, S. Resource-based competition and the new operations strategy. International Journal of Operations \& Production Management, v. 19, n. 2, p. 125-138, 1999. crossref

GONÇALVES, A. T. P.; LEITE, M. S. A.; SILVA, R. M. Um estudo preliminar sobre as definições e as diferenças dos principais tipos de arranjos empresariais. Revista Produção Online, v. 12, n. 3, p. 827-854, 2012. cross ref

GRETZINGER, S.; ROYER, S. Relational resources in value adding webs: the case of a Southern Danish firm cluster. European Management Journal, v. 32, p. 117-131, 2014. cross ref

HOCAYEN-DA-SILVA, A. J.; TEIXEIRA, R. M. Análise dos relacionamentos interorganizacionais em empresas do setor hoteleiro de Curitiba: estudo comparativo de casos. Revista Brasileira de Pesquisa em Turismo, v. 3, n. 2, p. 2448, 2009. crossref

LAVIE, D. The competitive advantage of interconnected firms: an extension of the resource-based view. Academy of Management Review, v. 31, n. 3, p. 638-658, 2006. crossref

LEWIS, M. et al. Competing through operations and supply: the role of classic and extended resource-based advantage. International Journal of Operations \& Production Management, v. 30, n. 10, p. 1032-1058, 2010. crossref

LIN, Y.; WU, L. Exploring the role of dynamic capabilities in firm performance under the resource-based view framework. Journal of Business Research, v. 67, n. 3, p. 407-413, 2014. crossref

PARUNG, J.; BITITCI, U. S. A conceptual metric for managing collaborative networks. Journal of Modelling in Management, v. 1, n. 2, p. 116-136, 2006. cross ref

PERTUSA-ORTEGA, E. M.; CLAVER-CORTÉS, E.; MOLINA-AZORÍN, J. F. Competitive strategy, structure and firm performance: a comparison of the resource-based view and the contingency approach, Management Decision, $v$. 48, n. 8, p. 1282-1303, 2010. crossref

PETERAF, M. A. The cornerstones of competitive advantage: a Resource- Based View. Strategic Management Journal, v. 14, n. 3, p. 179-191, 1993. crossref

PIGATTO, G.; ALCANTARA, R. L. C. Relacionamento colaborativo no canal de distribuição: uma matriz para análise. Gestão \& Produção, v. 14, n. 1, p. 155-167, 2007. crossref

RUMELT, R. P.; SCHENDEL, D.; TEECE, D. J. Strategic Management and Economics. Strategic Management Journal, v.12, n. 8, p.5-29, 1991. crossref

RUNGTUSANATHAM, M. et al. Supply-chain linkages and operational performance: a resource-based-view perspective. International Journal of Operations \& Production Management, v. 23, n. 9, p. 1084-1099, 2003. crossref

SEBRAE. Arranjo Produtivo Local. Série Empreendimentos Coletivos. 44 p. 2009.

SAHAY, B. S. Understanding trust in supply chain relationships. Industrial Management \& Data Systems, v. 103, n. 8, p. 553-563, 2003. crossref

VASCONCELOS, F. C.; CYRINO, A. B. Vantagem competitiva: os modelos teóricos atuais e a convergência entre estratégia e teoria organizacional. Revista de Administração de Empresas, v. 40, n. 4, p. 20-37, 2000. crossref 
VIANA, F. L. E. ; BARROS NETO, J. P.; AÑEZ, M. E. M. Gestão da cadeia de suprimento e vantagem competitiva relacional na indústria de calçados. Revista Produção Online, v.14, n. 4, p.1404-1432, 2014. crossref

WERNERFELT, B. A resource-based view of the firm. Strategic Management Journal, v. 5, n. 2, p. 171-180, 1984. crossref

WILK, E. O. A relação entre estratégias, recursos e performance: Uma investigação em empresas de vinhos finos do cluster da Serra Gaúcha. Tese - Programa de Pós-Graduação em Agronegócios, Universidade Federal do Rio Grande do Sul, Porto Alegre, 2006.

WILK, E. O.; FENSTERSEIFER, J. E. Use of resource-based view in industrial cluster strategic analysis. International Journal of Operations \& Production Management, v. 23, n. 9, p. 995-1009, 2003. crossref

WU, X. et al. Shared resources and competitive advantage in clustered firms: the missing Link. European Planning Studies, v. 18, n. 9, p. 1391-1410, 2010. crossref

YIN, R. K. Estudo de caso. Planejamento e métodos. 3. ed. Porto Alegre: Bookman, 2005.

\section{Dados dos autores:}

\section{Nome completo: Cinthia de Azevêdo Faustino}

Filiação institucional: Universidade Federal da Paraíba

Departamento: Engenharia de Produção

Função ou cargo ocupado: Mestranda

Endereço completo para correspondência: UFPB - Universidade Federal da Paraíba, Departamento de Engenharia de Produção, Centro de Tecnologia - Campus I, Bloco G, Cidade Universitária, João Pessoa - PB, Brasil - Cx. Postal: 5045 - CEP: 58.051-970

Telefones para contato: (83) 3216-7549

E-mail: cinthiafaustino@gmail.com

Nome completo: Cláudia Fabiana Gohr

Filiação institucional: Universidade Federal da Paraíba

Departamento: Engenharia de Produção

Função ou cargo ocupado: Professora

Endereço completo para correspondência: UFPB - Universidade Federal da Paraíba, Departamento de Engenharia de Produção, Centro de Tecnologia - Campus I, Bloco G, Cidade Universitária, João Pessoa - PB, Brasil - Cx. Postal: 5045 - CEP: 58.051-970

Telefones para contato: (83) 3216-7549

E-mail: claudiagohr@ct.ufpb.br

Submetido em: 16-05-2016

Aceito em: 21-09-2016 